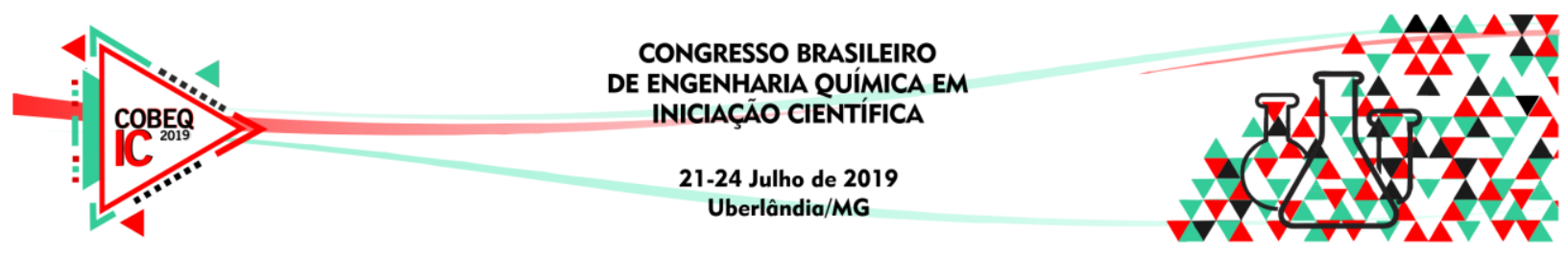

\title{
ANÁLISE COMPARATIVA DE MATRIZ POLIMÉRICA COM REJEITO INDUSTRIAL DE CAULIM E COBRE
}

\author{
J. E. A. SANTOS ${ }^{1}$, D. C. P. CRUZ ${ }^{1}$, I. F. G. CASTRO ${ }^{1}$, A. J. G. SANTOS ${ }^{2}$ e J. A. S. \\ SOUZA $^{1}$ \\ ${ }^{1}$ Universidade Federal do Pará, Faculdade de Engenharia Química \\ ${ }^{2}$ Universidade Federal do Pará, Campus Belém, Departamento de Engenharia Química \\ E-mail para contato: jaymesalmeida@ outlook.com
}

\begin{abstract}
RESUMO - A utilização de rejeitos industriais do setor da mineração no desenvolvimento de novas tecnologias sustentáveis na área de engenharia de materiais vem crescendo, sobretudo, pelas propriedades químicas e físicas dos rejeitos que possibilitam a combinação com os mais diversos materiais para a confecção de compósitos. Por esse motivo, neste trabalho são fabricados compósitos com matriz polimérica e inserção de rejeitos industriais de caulim e cobre, utilizando-se de resina poliéster com acelerador de cobalto e catalisador na confecção da matriz, onde há a variação nas proporções de $10 \%$ a $40 \%$ de inserção dos rejeitos. Os rejeitos foram caracterizados por meio de Difração de Raio X - DRX e os compósitos confeccionados a partir desses rejeitos sofreram ensaios mecânicos de resistência a tração segundo a norma ASTM D3039. Após a realização dos ensaios observou-se a boa ancoragem do rejeito de caulim e cobre na matriz polimérica utilizando-se das caracterizações morfológicas das superfícies de fratura através de Microscopia Eletrônica de Varredura - MEV para essa conclusão.
\end{abstract}

\section{INTRODUÇÃO}

Segundo Silveira (2015), no setor industrial, sobretudo no setor da mineração, é notório o crescimento da consciência pelo desenvolvimento socioambiental, tal desenvolvimento implica na busca por otimização dos recursos naturais que são explorados e também pela reutilização dos rejeitos indesejados que são gerados nos processos; a reutilização desses rejeitos implica na diminuição dos impactos econômicos, sociais e ambientais desde setor, porém é necessário o desenvolvimento de novas tecnologias para a reutilização adequada desses rejeitos; essas tecnologias, sobretudo, precisam ser economicamente viável.

Segundo Almeida (2012), um dos seguimentos de novas tecnologias para destinar os rejeitos industriais indesejados, está o desenvolvimento de materiais compósitos com matriz polimérica, esses materiais compósitos diminuem o acúmulo desses rejeitos e geram materiais componentes de interesse para a aplicação em algumas indústrias, como exemplo da construção civil. Os materiais compósitos são constituídos por duas ou mais fases de diferentes composições e estruturas, onde as propriedades se combinam, a mesma possui uma fase conhecida como matriz, que garante a ligação e outra fase conhecida como reforço, que garante a resistência. 


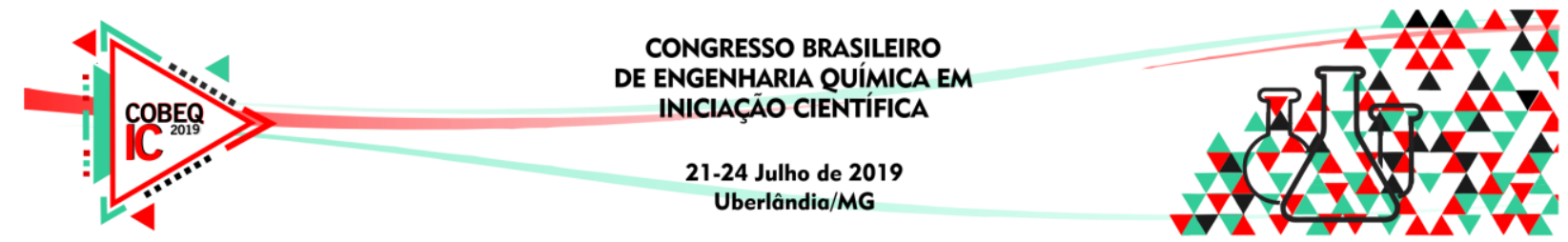

Segundo Ventura (2009), na tentativa de desenvolver uma tecnologia que seja economicamente viável, sendo assim baixando os custos de fabricação dos produtos e diminuindo os impactos socioambientais causados, ocorre a utilização de cargas de rejeitos minerais. Além dos motivos citados acima, os rejeitos de mineração apresentam propriedades de resistência e dureza que são importantes características para os materiais desenvolvidos, dada a importância de suas propriedades químicas e físicas a escolha desses materiais.

No desenvolvimento desse trabalho utilizou-se dois materiais residuais de processos industriais: O caulim e o cobre, e produziu-se compósitos de matriz polimérica com inserção de rejeito industrial, para analisar as propriedades adquiridas submeteu o material a ensaio mecânico de tração e posteriormente foram analisadas as características de fratura por meio da microscopia eletrônica de varredura.

\section{METODOLOGIA}

\subsection{PREPARAÇÃO E CARACTERIZAÇÃO DOS REJEITOS INDUSTRIAIS}

Os rejeitos industriais de caulim e cobre foram doados pelas empresas mineradoras Imerys Caulim, localizada no município de Ipixuna do Pará e VALE S.A, originário da Mina do Sossego, localizada no município de Canaã dos Carajás no estado do Pará. A preparação dos materiais foi realizada mediante a submissão dos rejeitos à operação de secagem em estufa por 24 horas, à temperatura de $105^{\circ} \mathrm{C}$. Posteriormente os rejeitos industriais sofreram peneiramento manual em peneira de granulometria 100 mesh da série Tyler.

Os rejeitos de caulim e cobre foram caracterizados por meio de Difração de Raio-X (DRX), com o intuito de verificar os minerais presentes na amostra. Para a análise foi utilizado um difratômetro de Raios - X: D8 Advance da Bruker, com tubo de Raios - X. A aquisição dos dados foi realizada com software X Pert Data collector, versão 3.0, o tratamento dos dados com software X Pert High Score Plus, versão 3.0, da PAnalytical consultando o banco de dados PDF (Power Diffaction File) do ICDD (International Center for Diffraction Data).

\subsection{PRODUÇÃO DOS COMPÓSITOS}

Utilizou-se no referido trabalho o polímero poliéster isoftálica (Resina AM 910 AEROJET), de média reatividade, amarelada, não acelerada, com baixa viscosidade. Acelerador de Cobalto, produto comercial denominado CAT MET UMEDECIDO (Solução de Octoato de cobalto 1,5\%). Utilizou-se o agente de cura catalisador, produto comercial BUTANOX M-50.

Para a produção dos compósitos utilizou-se um molde metálico na forma retangular nas dimensões de $320 \mathrm{~mm}$ x 172,5 mm x $5 \mathrm{~mm}$. Utilizou-se uma balança analítica para determinar previamente as massas da resina e do rejeito necessários para cada placa de acordo com sua porcentagem. A mistura foi colocada no molde e em seguida prensada, em prensa hidráulica com carga de $2,5 \mathrm{kN}$ durante o tempo estimado de 20 minutos. Após a produção 


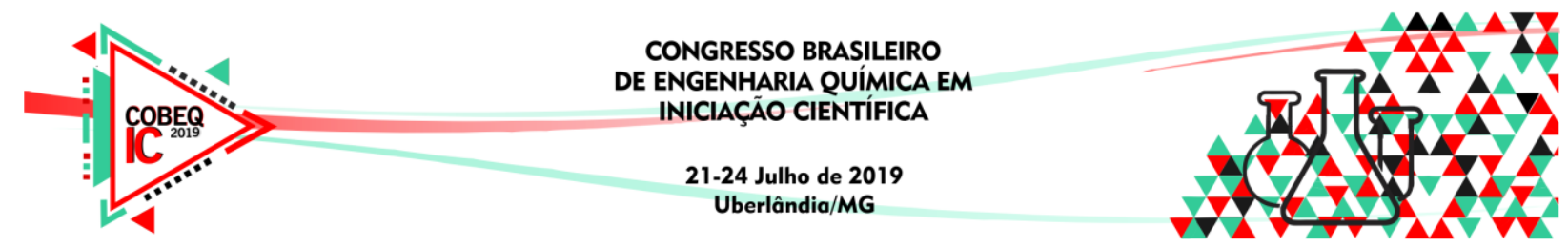

das placas, foram realizados os cortes nas placas, segundo Lima (2006), de acordo com a norma ASTM D3039.

\subsection{PROPRIEDADE MECÂNICA}

O ensaio de resistência à tração dos compósitos foi realizado na máquina universal de tração, marca KRATOS 1, modelo IKCL3 com sistema de aquisição de dados, com célula de carga de $5 \mathrm{kN}$, adotando velocidade de $2 \mathrm{~mm} / \mathrm{min}$ e comprimento útil para medição entre garras de $180 \mathrm{~mm}$. Os ensaios de tração foram realizados seguindo a norma ASTM D- 3039 e adotaram as seguintes medidas: $250 \mathrm{~mm}$ de comprimento; $25 \mathrm{~mm}$ de altura e $2,5 \mathrm{~mm}$ de largura.

\subsection{MICROSCOPIA ELETRÔNICA DE VARREDURA}

Após a realização do ensaio mecânico, foi utilizado o microscópio eletrônico de varredura (MEV) X- Max, para analisar as superfícies de fratura dos corpos de prova, dessa forma observou-se as alterações morfológicas dos compósitos; as amostras sofreram um processo de metalização no tempo de 80 segundos.

\section{RESULTADOS E DISCUSSÕES}

\subsection{CARACTERIZAÇÃO DOS REJEITOS}

Através de uma análise difratométrica (DRX), foi possível detectar os principais componentes mineralógicos na amostra de rejeito de caulim, em ordem decrescente de intensidade a Caulinita (C) e o Quartzo (Q). A caulinita encontra-se em maior quantidade na amostra de resíduo de caulim analisada. Em ordem decrescente de intensidade, são apresentados os principais componentes mineralógicos da amostra de rejeito industrial de cobre; Quartzo (Q), Albita(A) e Magnetita (M) e o Clinocloro (C), conforme a figura 01.

Figura 1 - Resultados do DRX do caulim (esquerda) e do cobre (direita)
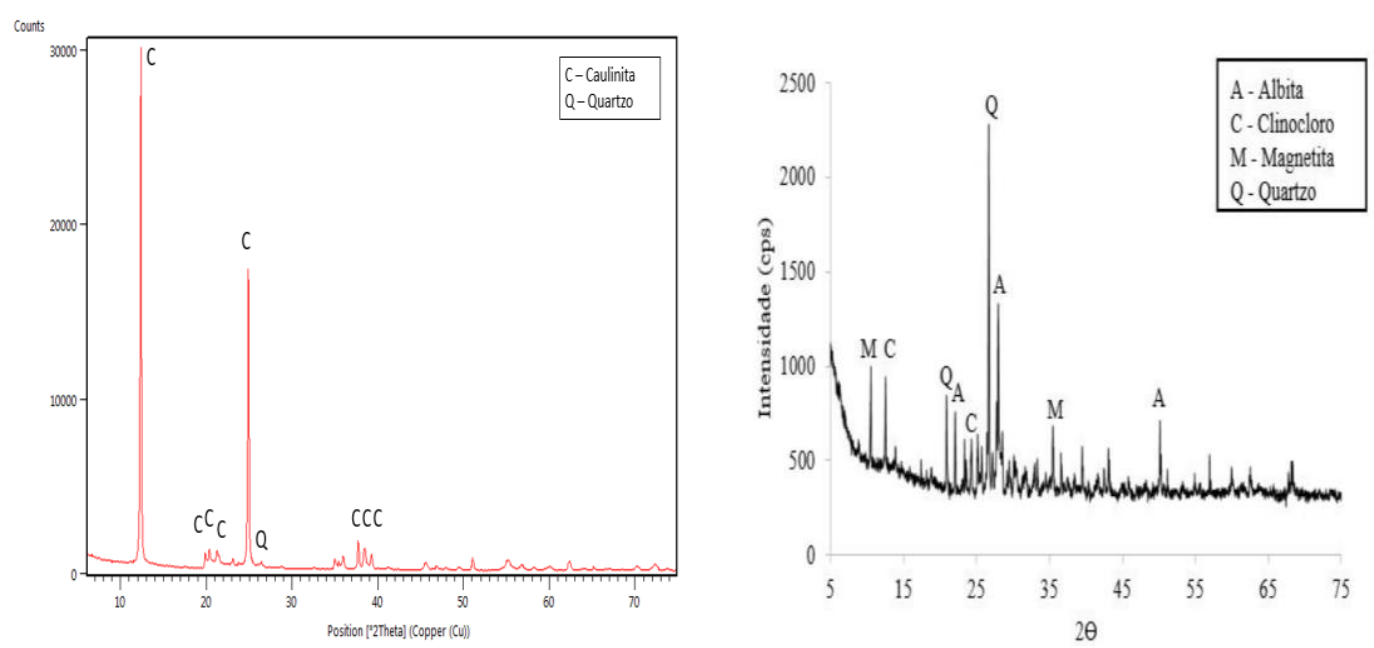

\subsection{PROPRIEDADES MECÂNICAS}




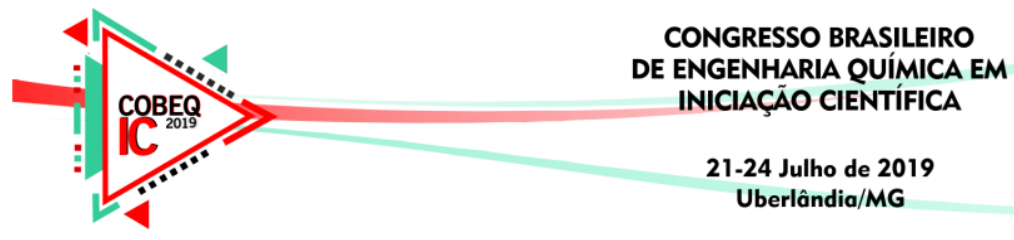

A avaliação dos compósitos poliméricos com inserção de rejeitos industriais deu-se quanto a sua resistência mecânica por meio do ensaio de tração, os resultados obtidos nesses ensaios são apresentados nas Tabelas 01 e 02.

Tabela 1 - Resultados de resistência à tração dos compósitos com inserção de rejeito industrial de caulim

\begin{tabular}{|c|c|c|c|c|c|}
\hline $\begin{array}{c}\text { Tipos de } \\
\text { amostra }\end{array}$ & $\begin{array}{c}\text { Proporção de } \\
\text { carga (\%) }\end{array}$ & $\begin{array}{c}\text { Fração mássica } \\
(\mathrm{FM})(\mathrm{g})\end{array}$ & $\begin{array}{c}\text { Resistência } \\
\text { tração (MPA) } \\
(\text { Desvio padrão) }\end{array}$ & $\begin{array}{c}\text { Alongamento } \\
(\mathrm{mm})\end{array}$ & $\begin{array}{c}\text { Módulo de } \\
\text { elasticidade } \\
(\mathrm{GPA})\end{array}$ \\
\hline \hline Matriz Pura & 0 & 317,40 & $19,54( \pm 3,05)$ & 4,84 & 0,81 \\
\hline \multirow{2}{*}{$\begin{array}{c}\text { Rejeito } \\
\text { industrial de } \\
\text { Caulim }\end{array}$} & $\mathrm{RCa} 10$ & 31,74 & $27,53( \pm 6,28)$ & 4,77 & 1,06 \\
\cline { 2 - 6 } & $\mathrm{RCa} 20$ & 63,48 & $30,78( \pm 6,56)$ & 4,70 & 1,24 \\
\cline { 2 - 6 } & $\mathrm{RCa} 30$ & 95,22 & $31,44( \pm 4,39)$ & 5,20 & 1,13 \\
\cline { 2 - 6 } & $\mathrm{RCa} 40$ & 126,96 & $27,77( \pm 2,49)$ & 5,87 & 1,19 \\
\hline
\end{tabular}

Através dos resultados dos ensaios de resistência à tração obtidos observou-se que tal resistência aumenta quando há adição de rejeitos industriais de caulim em relação a matriz plena, porém o aumento da resistência não ocorre em acréscimo do aumento da proporção incorporadas na matriz polimérica; isso pode ser comprovado visto que o ensaio realizado, que apresentou o comportamento superior, foi o de fração de $30 \%$ com tração de $31,44 \mathrm{MPa}$. Tal resultado pode ser explicado pelo fato de que a matriz polimérica possui boa reatividade com a caulinita presente predominantemente no rejeito de caulim, porém quando essa proporção satura (proporção de 40\%) os efeitos já não são mais sentidos na sua resistência.

Tabela 2 - Resultados de resistência à tração dos compósitos com inserção de rejeito industrial de cobre

\begin{tabular}{|c|c|c|c|c|c|}
\hline $\begin{array}{c}\text { Tipos de } \\
\text { amostra }\end{array}$ & $\begin{array}{c}\text { Proporção de } \\
\text { carga (\%) }\end{array}$ & $\begin{array}{c}\text { Fração mássica } \\
(\mathrm{FM})(\mathrm{g})\end{array}$ & $\begin{array}{c}\text { Resistência } \\
\text { tração (MPA) } \\
(\text { Desvio padrão) }\end{array}$ & $\begin{array}{c}\text { Alongamento } \\
(\mathrm{mm})\end{array}$ & $\begin{array}{c}\text { Módulo de } \\
\text { elasticidade } \\
(\mathrm{GPA})\end{array}$ \\
\hline Matriz Pura & 0 & 317,40 & $19,54( \pm 3,05)$ & 4,84 & 0,81 \\
\hline \multirow{2}{*}{$\begin{array}{c}\text { Rejeito } \\
\text { industrial de } \\
\text { Caulim }\end{array}$} & RCU 10 & 31,74 & $27,38( \pm 1,45)$ & 4,63 & 1,04 \\
\cline { 2 - 6 } & RCU 20 & 63,48 & $25,18( \pm 1,84)$ & 4,78 & 0,98 \\
\cline { 2 - 6 } & RCU30 & 95,22 & $32,83( \pm 2,81)$ & 5,12 & 1,14 \\
\cline { 2 - 6 } & RCU 40 & 126,96 & $40,25( \pm 1,88)$ & 5,46 & 1,39 \\
\hline
\end{tabular}

Para os resultados dos ensaios de tração realizados com rejeito industrial de cobre, observou-se que há um comportamento crescente, ou seja, os melhores resultados de resistência a tração encontram-se nas frações com maiores proporções de rejeitos. De acordo com Borges (2017), as propriedades de ductilidade, característica do cobre, são melhores aproveitadas quando há o aumento na proporção de rejeito de cobre na matriz, devido a isto, ocorre uma melhor homogeneização e uma melhor compactação devido as propriedades mineralógicas do quartzo, predominante nesse rejeito de cobre; por isso as frações de $30 \%$ e $40 \%$ apresentaram um comportamento superior.

\subsection{COMPARAÇÃO DOS RESULTADOS}

A partir do gráfico a seguir, figura 02, observa-se as diferenças no limite de resistência à tração nos rejeitos industriais de caulim e cobre com o aumento das proporções 


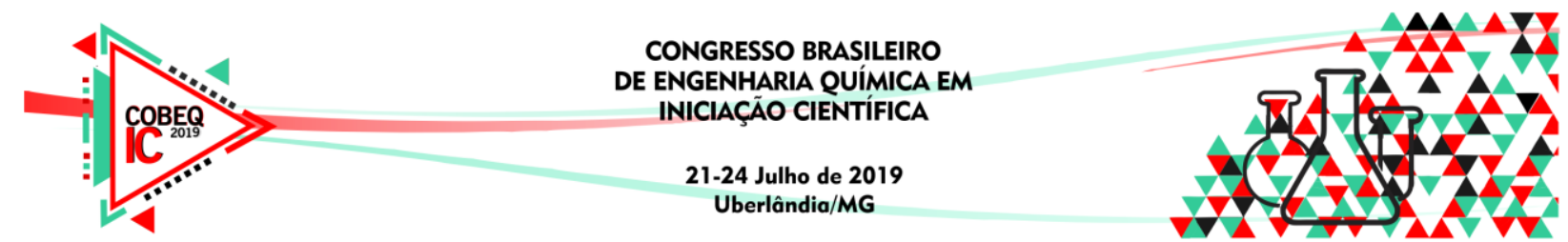

incorporadas na matriz polimérica, somente o compósito com inserção de rejeito de cobre na proporção de $40 \%$ obteve uma resistência a tração superior ao compósito com inserção de rejeito de caulim na mesma proporção. Nas demais proporções $(30 \%, 20 \%$ e $10 \%)$ o compósito a partir do rejeito de caulim apresentou uma resistência a tração superior ao compósito a partir do rejeito de cobre.

Figura 2 - Comparação do limite de resistência a tração de rejeitos

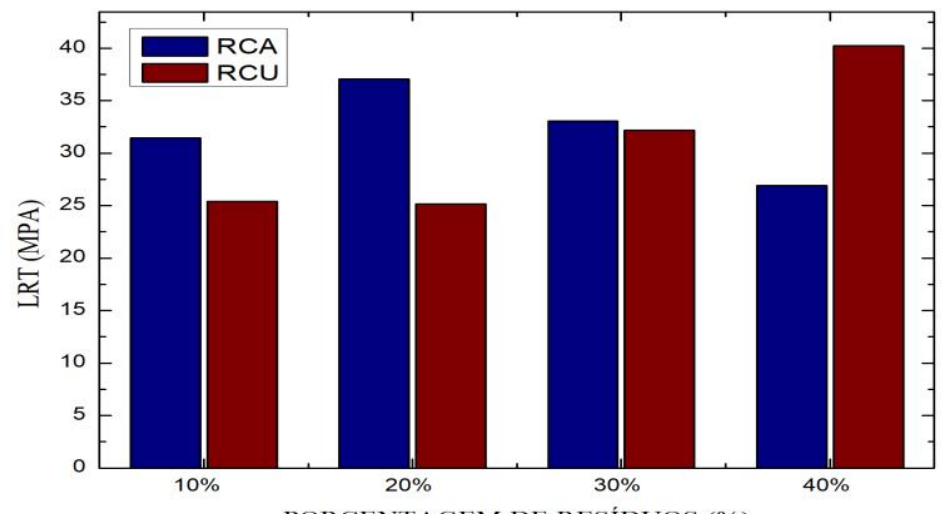

\subsection{MICROSCOPIA ELETRÔNICA DE VARREDURA (MEV)}

A figura 3 abaixo mostra-se as superfícies da região onde ocorreram as fraturas nos materiais após a realização dos ensaios de resistência a tração.

Figura 3 - MEV da fratura do compósito com carga mineral de caulim 40\% (esquerda) e cobre $40 \%$ (direita)

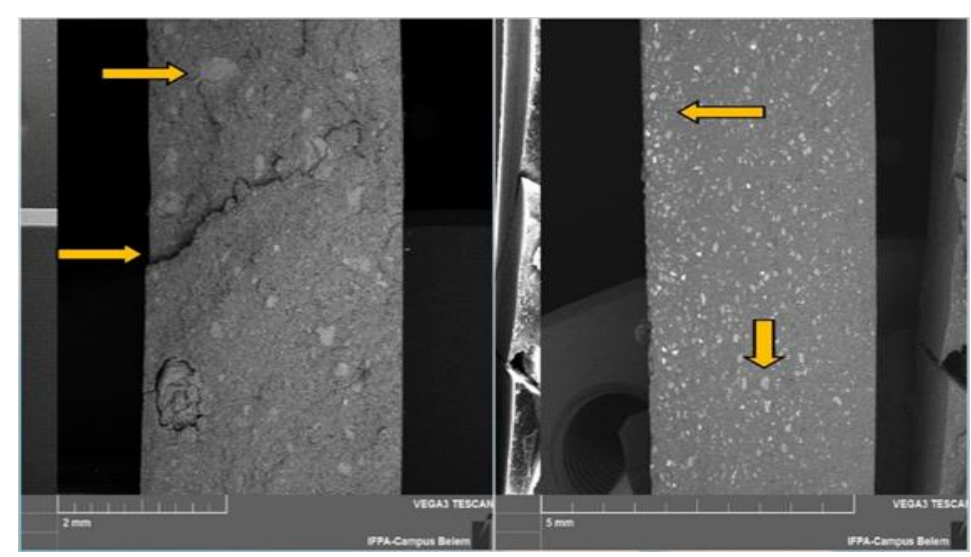

Nestas imagens observa-se a predominância e distribuição homogênea das partículas de cobre (lado direito) o que garantiram um aumento no limite de resistência a tração quando comparado ao de caulim (lado esquerdo) que não obteve uma homogeneização desejada o que implica nas fissuras apresentadas na imagem. 


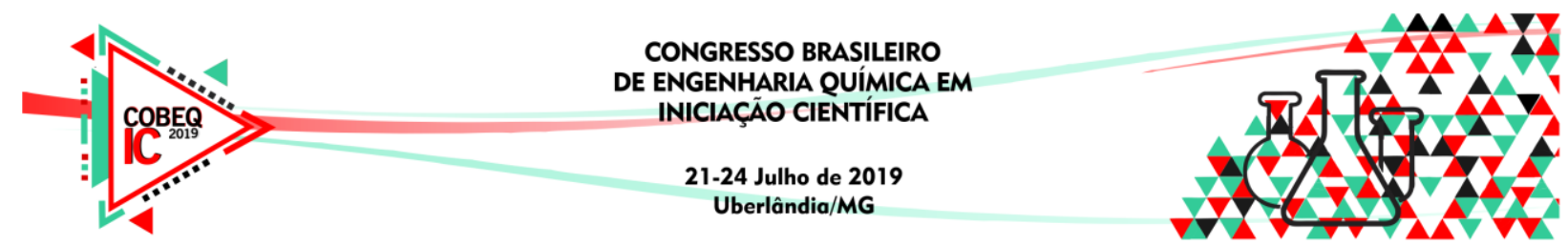

\section{CONCLUSÕES}

A metodologia utilizada para a confecção dos compósitos foi eficaz, visto que os compósitos fabricados obtiveram uma consistência de boa ancoragem dos rejeitos industriais de caulim e cobre na matriz polimérica.

Os ensaios de DRX possibilitaram caracterizar os rejeitos e assim estudar sua relação com as proporções de matriz poliméricas. Os compósitos a partir do rejeito de caulim obtiveram resultados superiores aos de cobre até a proporção de $30 \%$ pois a caulinita predominante nesse mineral, apresenta boa reatividade à matriz polimérica e para proporção superior estudada nesse artigo, apresentou saturação. Já os compósitos a partir do rejeito de cobre apresentam resistência elevada para proporções superiores, devido as características mineralógicas do quartzo, o que possibilitou ao compósito de cobre com proporção de $40 \%$ atingir o resultado superior de LRT de o valor de 40,25. Proporções superiores à de $40 \%$ devem ser analisadas para obter a proporção de saturação do compósito a partir desse rejeito.

As fraturas ocasionadas pelos ensaios de resistência a tração possibilitam a visualização das distribuições dos rejeitos de caulim e cobre nos compósitos fabricados, possibilitando caracterizar se houve homogeneização desejada para esses compósitos a partir da análise das superfícies expostas, pelo MEV.

\section{REFERÊNCIAS}

ALMEIDA, N. M. B. G ESTUDO ESTRUTURAL DE COMPÓSITOS DE MATRIZ POLIMÉRICA REFORÇADOS COM FIBRA DE JUTA. Faculdade de Engenharia da Universidade de Porto. Mestrado Integrado em Engenharia Mecânica. Porto. Portugal. 2012.

BORGES, D. R. Influência do uso de fibras de bambu (Bambusa Vulgaris) tratadas químicamente em compósitos de polímero termofixo carregadas com resíduo da indústria de beneficiamento de minério de cobre. 2018. 102f. Dissertação (Mestrado) - Programa de Pósgraduação em Engenharia Química (PPGEQ), Instituto de Tecnologia, Universidade Federal do Pará, Belém, 2018.

CALLISTER, William D., 1940- Ciência e engenharia de materiais: Uma Introdução/ William D. Callister, Jr., David G. Rethwisch; tradução Sergio Murilo Stamile Soares; revisão técnica José Roberto Moraes d' Almeida. - [Reimpr.]. - Rio de Janeiro: LTC, 2013.

LIMA, S. C. Estudo da técnica de difração de raios x. 2006. 69 f. Trabalho de conclusão de curso (Graduação em Física), Universidade Estadual de Feira de Santana, Feira de Santana, 2006.

SILVEIRA, M. D. UTILIZAÇÂO DE RESÍDUOS DE MINERAÇÃO NA CONSTRUÇÃO CIVIL. Universidade Federal de Minas Gerais. Curso de Especialização em Construção Civil. Belo Horizonta. Minas Gerais. 2015.

VENTURA, A. M. F. M. OS COMPÓSITOS E SUA APLICAÇÃO NA REABILITAÇÃO DE ESTRUTURAS METÁLICAS. Departamento de Engenharia Química e Biológica. Instituto Superior Técnico. Campus Alameda. Lisboa, Portugal 2009. 